\title{
Geoethics and geological culture: awareness, responsibility and challenges
}

\author{
Silvia Peppoloni, Giuseppe Di Capua
}

Istituto Nazionale di Geofisica e Vulcanologia, Rome, Italy

\author{
Article history \\ Received February 1, 2012; accepted March 1, 2012. \\ Subject classification: \\ Education, History of science, Public issues, General (Philosophy of Earth sciences).
}

\begin{abstract}
The international debate in the field of geoethics focuses on some of the most important environmental emergencies, while highlighting the great responsibilities of geoscientists, whatever field they work in, and the important social, cultural and economic repercussions that their choices can have on society. The Geoitalia 2009 and 2011 conferences that were held in Rimini and Turin, respectively, and were organized by the Italian Federation of Earth Science, were two important moments for the promotion of geoethics in Italy. They were devoted to the highlighting of how, and with what tools and contents, can the geosciences contribute to the cultural renewal of society. They also covered the active roles of geoscientists in the dissemination of scientific information, contributing in this way to the correct construction of social knowledge. Geology is culture, and as such it can help to dispel misconceptions and cultural stereotypes that concern natural phenomena, disasters, resources, and land management. Geological culture consists of methods, goals, values, history, ways of thinking about nature, and specific sensitivity for approaching problems and their solutions. So geology has to fix referenced values, as indispensable prerequisites for geoethics. Together, geological culture and geoethics can strengthen the bond that joins people to their territory, and can help to find solutions and answers to some important challenges in the coming years regarding natural risks, resources, and climate change. Starting from these considerations, we stress the importance of establishing an ethical criterion for Earth scientists, to focus attention on the issue of the responsibility of geoscientists, and the need to more clearly define their scientific identity and the value of their specificities.
\end{abstract}

\section{Introduction}

Geoethics is the study and promotion of the evaluation and protection of the geosphere. Even though geoethics is increasingly present in the scientific conferences (e.g. International Geological Congress, Mining Pribram Symposium, Geoitalia Conference, EGU General Assembly), its analyses and debates have not reached a significant maturity. This new discipline is not accompanied by an adequate research base and a satisfactory number of scientific publications, which are the essential references for its future development.

Also, the themes of geoethics cannot easily find space in the most reliable scientific journals, and this severely restricts the dissemination of their contents and the development of a critical stance towards the ethical, social and cultural implications of Earth sciences in the scientific community. The researchers are anxious to respond to the 'publish or perish' logic, and they often tend to neglect geoethics arguments, although some of them would like to devote themselves to the study of geoethics in depth. So research on geoethics, as a both scientific and humanistic discipline, is not developing, and its contribution to the correct construction of social knowledge is missing, such that society tends to become culturally poorer.

Based on these considerations, it is increasingly urgent to give greater strength and exposure to geoethics themes, so that they are recognized and appreciated by the whole scientific community. Geoethics needs to get out of confined areas of discussion and to become a moment of reflection, above all for geoscientists to have the opportunity to ask questions about themselves, the quality of their work, and their contribution to the healthy progress of humanity.

\section{Geoethics themes}

The international debate in the field of geoethics focuses on some of the most important environmental emergencies, like the greenhouse effect and climate destabilization, and pollution and problems of waste disposal. Geoethics is concerned to encourage critical analysis of the use of our natural resources, to promote correct information of natural hazards and the development of environmentally friendly technologies, while also extending its principles to planetary protection [Martínez-Frías et al. 2011]. It is a discipline that is targeted primarily to provide references and guidelines of behavior in relation to concrete prob- 
lems of human life, and to seek the appropriate solutions.

Among its intents, there is also the promotion of the social role of the geosciences, to involve the community in the idea of a common and shared 'geological' heritage, which is considered as having cultural, educational and scientific value, as well as social capital. So, the goal of the geosciences is to steer society into the choice of appropriate behaviors towards real problems of human life, to try to find solutions that are compatible with the protection of Nature and territory.

The international debate has highlighted the great responsibilities of geoscientists, whatever field they work in (public or institutional fields, the private sphere, or the world of research, teaching or scientific information), and the important social, cultural and economic repercussions on society of their choices [Varet 2007]. This is especially true when problems related to natural hazards are considered, and in Italy this aspect is particularly evident [Di Capua and Peppoloni 2009, Peppoloni 2009].

Geoethics should promote reflection and consideration of the following themes:

- the comparison with global geological problems, so as to identify in the complexity those elements that, although distinguishing, can unite in pursuit of common goals;

- the rational and sustainable use of our georesources;

- the proper and correct dissemination of the results of scientific studies and of responsible information on risks, which allows researchers to gain the confidence of the community, to ensure the quality of research products;

- the help towards efficient management of emergencies, to protect the community from geological hazards at critical moments;

- the improvement of the relationships between the scientific community, the mass media and public opinion, through constant and qualified participation in the spaces offered by the media;

- the respect of the law and the support of policy decisions:

- the organization of effective teaching tools to develop awareness, values and correct behavior;

- the identification of new elements, both in terms of content and activities, that can be directed towards new relations and cultural and ethical views;

- the transfer of the cultural values of the environment to those who inhabit it;

- the promotion of working groups within universities and professional associations, for the development of the topics listed above, also with a flexible and prudent perspective for the reconsideration of scientific certainties and for reflection on the mutability of knowledge and roles.

\section{Geological culture}

James Hutton (1726-1797), Charles Darwin (18091882 ) and Alfred Wegener (1880-1930) contributed actively to change the cultural horizons of their times (Figure 1). In his theory of 'Deep Time', Hutton was the first to intuit the real age of the Earth: millions of years, and not only the 6,000 years deduced from the Bible. Darwin challenged the view of the nineteenth century Creationists, arguing that man descended from monkeys, and is one of the many species produced by evolution. In the early twentieth century, Wegener cast the certainties of the Autoctonists into crisis by asserting that the continents are rafts adrift on the surface of the Earth.

These geoscientists influenced the cultural world of their times, and they revolutionized the way in which humans perceive themselves, by changing their references of space and time. Today, they are considered among the fa-
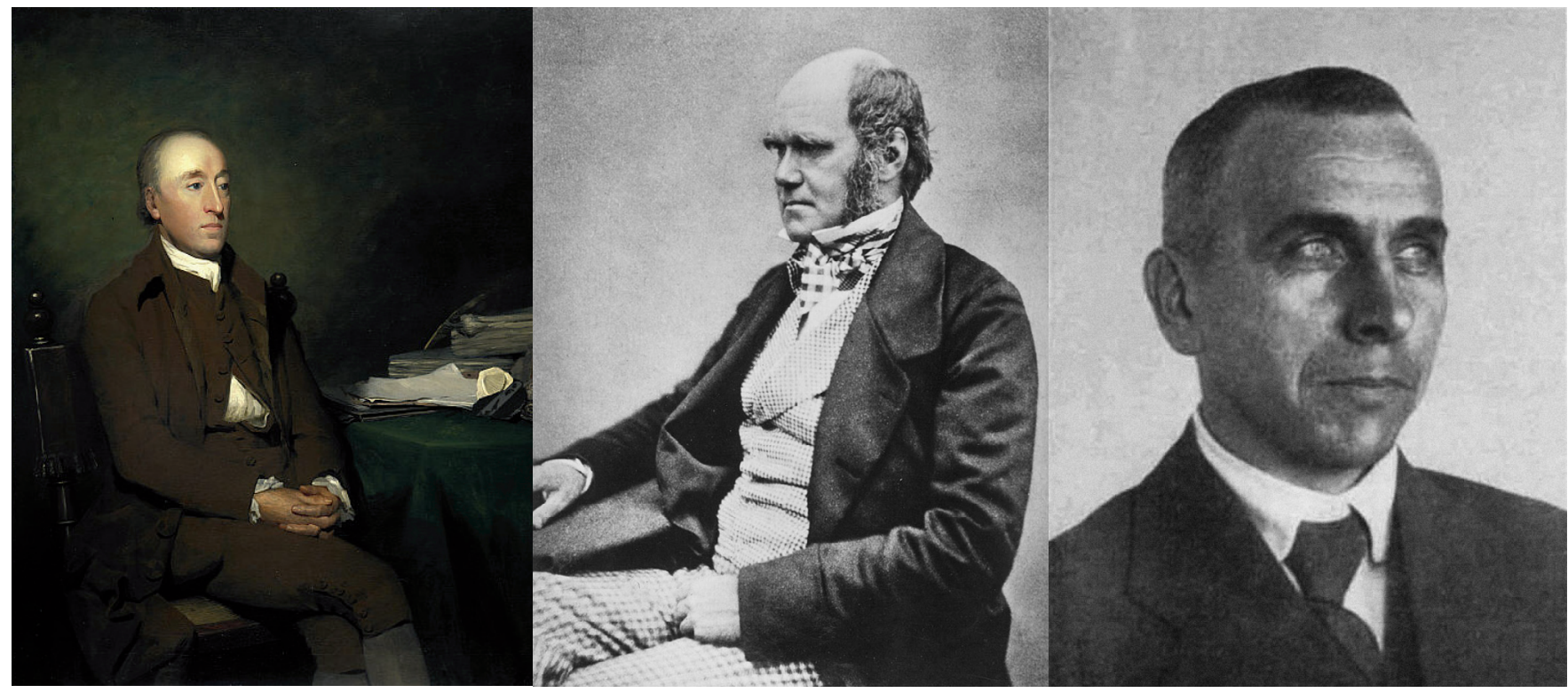

Figure 1. Left to right: James Hutton (1726-1797), Charles Darwin (1809-1882), and Alfred Wegener (1880-1930) (from http:/ / en.wikipedia.org). 
thers of modern geology, although they were strongly obstructed by the defenders of knowledge who were considered most authoritative in their times.

Culture is the soul of civilization, and it is not only fixed ideas and constraints. Science is culture. Geology (in the broad and noblest sense of the term) is a science. Thus, geology is culture, and as such, it can help to dispel misconceptions and cultural stereotypes concerning natural phenomena, disasters, resources and land management. Geological culture consists of methods, goals, values, history, ways of thinking about Nature, and a specific sensitivity for approaching problems and their solutions [Peppoloni 2007, 2008]. So in the approach to the problems concerning the relationships between man and Nature, geology should not be reduced only to codes of behavior.

Together with other sciences, geology has helped extraordinarily and originally to change the way in which we perceive time and space. Geology has posed problems of philosophy, and has made, and makes, culture; we have no geoethical solutions if we do not consider geology as a part of our culture.

\section{Geoethics and geological culture in Italy}

The reflection on the ethical aspects of the geosciences started in Italy around the 1970's, within the wider debate on the philosophy and sociology of the Earth sciences. Some geoscientists began to reflect on the ethical value of their geological knowledge. One of the promoters of these reflections was Felice Ippolito (1915-1997), a geologist and also an engineer. Although Ippolito was not a philosopher, he developed philosophical topics related to the geosciences, such as the relationships between geoscientists and Nature. He wondered what kind of science geology is, what is its way of investigating (both through mathematical models and through the observation of real phenomena), as it is halfway between an exact science, like mathematics, and an empirical science. He considered the social value and function of our technical-scientific knowledge, and then the relationships between geosciences and policy. He emphasized that who has scientific knowledge must assume the responsibility to act in an ethical sense, turning this technical knowledge into ethical action, so taking into account the common good and the public use [Ippolito 1968]. Ippolito's reflections demonstrated a longstanding commitment by Italian geoscientists to philosophical, social and ethical themes related to their geological activities, even before all of this set of issues was defined with the word 'geoethics' [Nemec 2005].

Along these lines, from the 1970 's to date, several studies on geological knowledge in terms of culture have been produced by Sandra Piacente and Mario Panizza [Panizza 1989, Panizza and Piacente 1991, Piacente 1999, Panizza and Piacente 2003, Piacente and Poli 2003]. Their contributions have provided a new way of understanding geology, of going beyond simple definitions, to outline new perspectives for the geosciences. They fostered improved understanding of the value of geological heritage as an element of cultural identity, not exclusively attributable to local territorial realities, but generalizable to the whole experience of our human race. Over time, the studies of these and other Italian authors contributed to the achievement of concrete and prestigious objectives, as in 2009, with the recognition of the Dolomites by UNESCO as a World Heritage Site (Figure 2).

Since 2000, thanks to Sandra Piacente, Caesare Roda and Carlo Bosi, sessions within the Geoitalia conferences have been organized, not only as strictly technical, but also dedicated to general topics, such as epistemological research in Earth sciences. In 2009, for the first time in Italy, a session on geoethics was organized, followed by a second session in 2011. The large number of participants, the quality of the contents that were offered, and the growing interest in these topics led to the creation of a Geoethics Committee within the Italian Federation of Earth Sciences (FIST), which brings together all of the most important associations of geoscientists and research institutions in Italy. The Geoethics Committee is working with the intent of promoting and evaluating geoethics themes, and of organizing events on geoethics: among the various proposals, the most original is the formulation of an oath for geoscientists, modeled on that of the Hippocratic Oath for doctors [Matteucci 2012, this issue], which will support and motivate new graduates on their Graduation Day; i.e. at the moment of their official entry into the world of geoscientists.

The last important event on geoethics was promoted by Italian geoscientists in an international venue (together with English, American and Norwegian colleagues): the session organized for the first time at the European Geosciences Union (EGU) General Assembly (Vienna, April 2012). The session focused on geoethics in relation to natural hazards, with specific attention to the communication, education and science-policy-practice interface. Twentyfour authors from 15 different countries offered reflections on the future of our planet, on ethical questions in risk management, on significant differences between problems in developing and developed countries, on scientific communication for risk reduction, on the choice of tools and strategies to increase awareness about risks, on education in schools, and on the relationships between geoscientists, the mass media, politicians and the population.

\section{The Geoitalia conferences}

The Geoitalia 2009 (Rimini) and 2011 (Turin) conferences organized by FIST were two important moments for the promotion of geoethics in Italy. Researchers and 


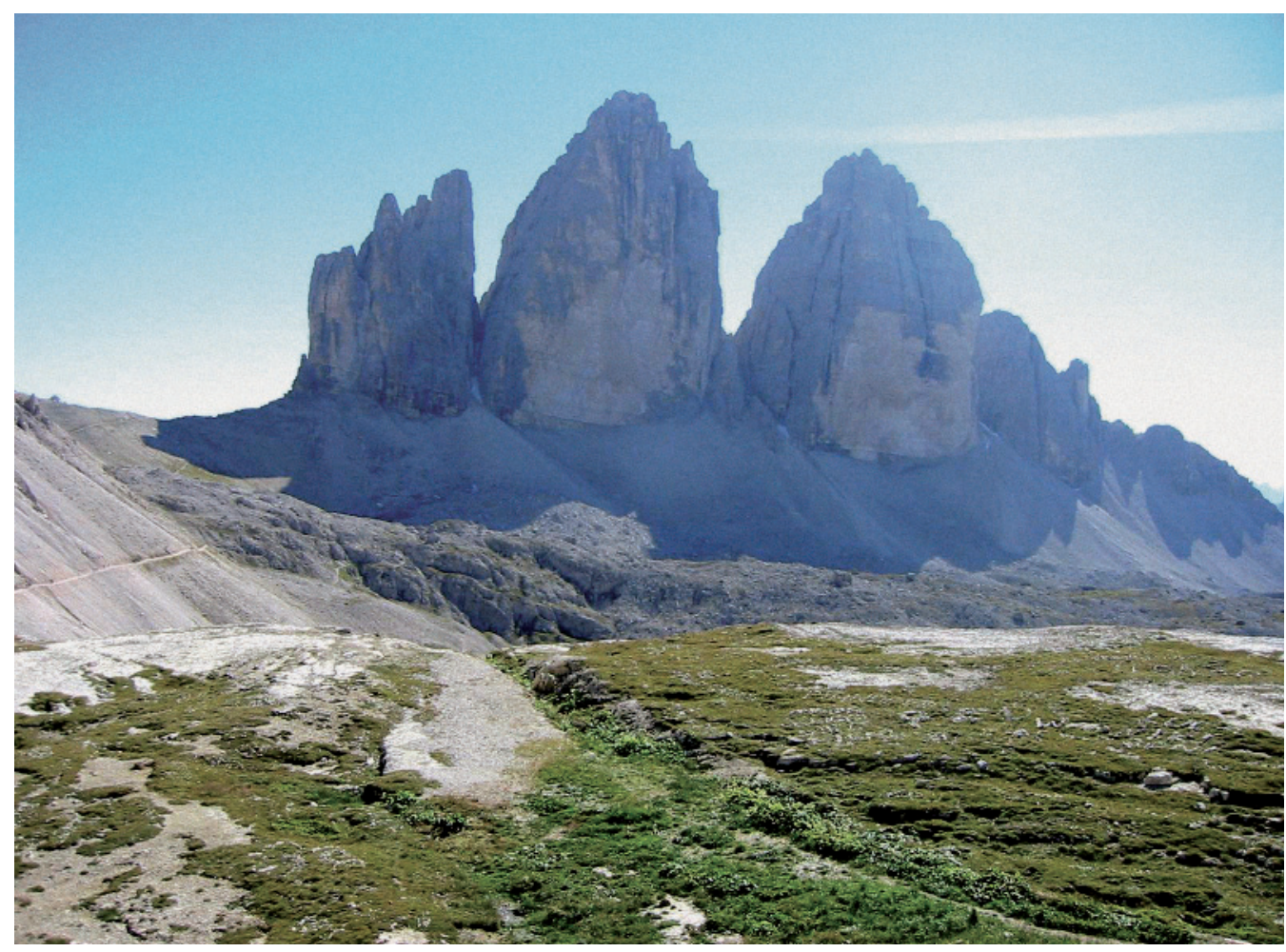

Figure 2. The Dolomites (from http:/ /it.wikipedia.org/wiki/Dolomiti).

a subject that should assist with correct scientific information, of the underestimated role of geoscientists in Italy, and of Italian society that is still not accustomed to listening to their warnings [Peppoloni 2012a, this issue].

Prof. Giorello (one of the most prominent philosophers of science) praised the important contribution of the Earth sciences in the promotion of the major cultural changes that have occurred through history, framing this set of disciplines in ethical and epistemological terms. He spoke about the precau-

professionals from different disciplines reflected on and discussed the most effective strategies and methodological approaches that need to be put into place for developing appropriate attitudes and forms of critical thinking on these issues. In 2009, in Rimini, the first Italian session on geoethics was a comforting success. The theme of the session was a reflection of the cultural and social responsibility of geologists in the third millennium. In 2011, in Turin, this success was confirmed, with the participation of 34 speakers, a number that exceeded even that of the international session at the 33rd IGC in Oslo (2008) and other international meetings where geoethics is usually among the disciplines debated. The speakers covered many disciplinary fields, and geologists, philosophers, sociologists, geophysicists, seismologists, psychologists, naturalists, anthropologists, and many others, attended the session. This thus gave the signal that a multidisciplinary approach to geoethics topics is helpful, to contribute to a cultural renewal of society. This is necessary and urgent for an increased awareness of the responsibilities of humanity with respect to environmental change, and with respect to exploitation of territories and of their resources.

With the aim of opening the world of the Earth sciences to the wider world of culture, and of looking for different viewpoints about not only the technical-scientific role, but also the cultural role of geoscientists, even some prominent intellectuals were invited to the session. Prof. Franco Ferrarotti (Professor emeritus and world-famous sociologist) emphasized the strong social impact of geological research and practice, speaking of the media as tionary principle, the uncertainty concept in the Earth sciences, and the probability calculation as a tool for the evaluation of natural risks. He also reflected on the relationships between politicians and citizens, by defining geology as "a red thread that allows us to go ahead" [Peppoloni 2012b, this issue].

Other contributions regarded geological risks and the public sentiments about them, deontological aspects of geological practice, with particular reference to issues of legality, evaluation criteria of geological research, the role of geologists working in public administration, importance of geological didactics in schools, sustainability and georesources exploitation, geodiversity, and cultural and social aspects in land management.

\section{Individual and social responsibility of geoscientists}

If it is true that geoethics is the investigation and reflection on the operational behavior of man towards the geosphere, it is therefore necessary to identify a criterion for the selection of values on which to base that behavior so that it is ethically correct. However, the question regarding the responsibilities of those working in the field of the geosciences has to be discussed, putting the geoscientists at the centre of the ethical matters [Peppoloni 2008], as experts on the territory and on all its hazards, as researchers, and as operators in public and institutional fields, in professional spheres, and in the fields of education and science communication. In each of these fields, the importance of the role that geoscientists have in society is evident, with the need to define in a better way the 
scientific identity of geoscientists, the values of their specificity. Finally, there is the need to requalify their professionalism, beginning from a more aware taking on of responsibility in the tasks that they have to perform.

An in-depth etymological analysis of the word 'geoethics' [Peppoloni 2011] disclosed an original double meaning: on the one hand, it contains a sense of belonging to the social dimension, while on the other hand, it is related to the individual sphere. These two existential conditions (social and individual) co-exist unexpectedly in the word 'geoethics'. So, geoethics can be defined on one hand as investigation and reflection on the operational behavior of man towards the geosphere, and on the other hand as the analysis of the relationships between geoscientists who act, and on their own actions.

Therefore, the origin of the word 'geoethics' gives geoscientists the indication that they cannot ignore the ethical aspect of their activities. The etymology of 'geoethics' calls geoscientists to face this responsibility. However, what does this responsibility of geoscientist consist of? And what motivations are needed to push geoscientists to practice the Earth sciences in an ethical way?

\section{An ethical criterion for the scholars of the Earth}

Werner Heisenberg (Figure 3) asserted : "Natural science not simply describes and interprets Nature, but it is a part of the interface between Nature and ourselves..." [Heisenberg 1958]. This means that through their activities and their personal research, the scholars of Nature, and therefore also geoscientists, have the opportunity to perfect themselves.

As geoscientists are searchers after truth, their scientific research or their professional activities might therefore constitute for them the way to their personal contact with the truth of the phenomena they study, and at the same time with the truth about themselves. It is primarily for self-respect that scientific truths have to be affirmed with intellectual honesty, so that research makes sense and scientific discoveries are transformed into a real service to society. The knowledge and experience of these phenomena makes us assume a habit of appropriate behavior, which becomes a personal and social discipline that as geoscientists, we have to follow in the management of our Earth.

Therefore, it is important to establish the ethical criteria for Earth scientists, fixing intellectual honesty precisely as the indispensable prerequisite. This requires:

- respect for the truth that we look for, and for the ideas of others;

- recognition of the value of others, as valuable for ourselves;

- a spirit of collaboration and reciprocity;

- identification of a common goal, despite the diversity of views;

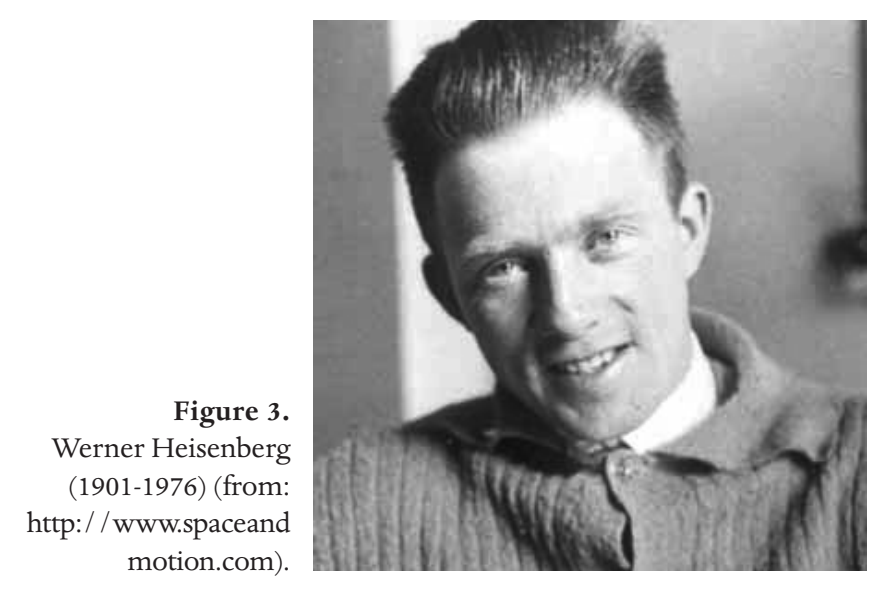

- responsibility of our technical-cultural expertise and care for the quality of research and its correct dissemination;

- opening to comparisons, even with the perspective of a resizing of our certainties;

- reflection on the mutability of knowledge and roles;

- awareness that conveying scientific knowledge to others has great value.

In line with these considerations, in the same moment in which geoscientists are involved in scientific or professional activities, on the one hand they assume the responsibility to put their expertise to the service of others, and on the other hand they have the responsibility towards themselves to do their best, aware of the commitments given. The results that we reach with our activities must be guided by respect for the truth of knowledge and intellectual honesty. Otherwise our activities are emptied of meaning. Only on this basis can our activities become a real service for others.

\section{Cultural, social and ethical implications of the geosciences, and future challenges}

Geological culture and geoethics can strengthen the links between people and their land, between the places of their origins and their own memories. These links are a great resource in a reality such as the Italian one, where cultural and natural heritage are often indivisible: man, art and Nature together constitute the territory. The awareness of the importance of their value, a common value to be shared and from which to draw upon, can encourage the identification of new elements, both in terms of the contents and the activities, which serves to direct us towards new cultural, social and ethical perspectives.

Geoethics is a great opportunity for the scientific community to provide formal and substantial value to the commitment of science for the benefit of citizens and institutions. Moreover, like any other sciences, the geosciences have a value especially in reference to the improvement of human qualities and to the satisfying of human needs. The great challenge of geoethics is above all to awaken in the scientific community reflection on its characteristics and prerogatives. We need to question some 
significant points so that the debate on geoethics makes progress in the coming years. These should include:

- How to identify and articulate an ethical criterion for geoscientists?

- Where should the line be drawn between preservation and economic development of the geosphere, especially in low-income countries?

- How can the freedom of research and actions be combined with the principles of sustainability?

- How can the relationships between geoscientists, the media, politicians and citizens be made more profitable, particularly in the defense against natural hazards?

- What communication and educational strategies should be adopted to transfer the value of the geosciences to society?

Many researchers have been occupied for years in the search for the answers to these questions, but the answers we have even now are not yet sufficient. Perhaps it is necessary that next to 'doing' and 'how to do', geoscientists must feel even more strongly the need to reflect on the value of their acting, because only a conscious and genuine recognition of the profound value of an action can allow the effective transfer to the community of those values. In this way we can foster a real and long-lasting rootedness of practices, codes and regulations.

A great historical responsibility is in the hands of the geoscientists of the third millennium: to demonstrate that geological knowledge is really a benefit to humankind, and that their contribution can be decisive in searching for a new equilibrium in the relationships between man and Nature. However, to move in this direction and to obtain concrete results, it will be necessary to develop the awareness of being able to do, to assume the responsibility to do, and to maintain this with a constant will.

\section{Conclusions}

Geoethics does not exist without a real awareness by the scientific community of the cultural value of the Earth sciences. Otherwise, there is the risk that geoethics will become just another bureaucratic constraint on the freedom of research and actions, a new set of bonds imposed but not perceived in their value, to limit practices and ideas. Geoethics can become a pretext to lock up the researcher and the whole of society in a moralistic way, in the contraposition between what is right and what is wrong, what we have to do, and what not to do. Instead, geoethics has to be above all an opportunity for geoscientists to raise the awareness of their individual and social responsibility, an occasion to improve our understanding of the space and time in which we move and operate, with the perspective of the spiritual and economic progress of humanity.

\section{References}

Di Capua, G., and S. Peppoloni (2009). Scientific information: problems and responsibilities, In: Proceedings of the Mining Pribram Symposium, International session on Geoethics, Pribram (Czech Republic); available at www.earth-prints.org/handle/2122/ 5455.

Heisenberg, W. (1958). Physics and philosophy: the revolution in modern science, Harper \& Brothers Publishers, 206 pp.; consulted edition: Fisica e filosofia, Milano, Nuove Edizioni Tascabili, 2003.

Ippolito, F. (1968). La natura e la storia, Milano, Vanni Scheiwiller.

Martínez-Frías, J., J.L. González and F. Rull Perez (2011). Geoethics and deontology: from fundamentals to applications in planetary protection, Episodes, 34 (4), 257-262.

Matteucci, R., G. Gosso, S. Peppoloni, S. Piacente and J. Wasowski (2012). A Hippocratic Oath for geologists?, Annals of Geophysics, 55 (3), 365-369; doi:10.4401/ag5650 .

Nemec, V. (2005). Developing geoethics as a new discipline, http: / / www.bgs.ac.uk/agid/Downloads/VN05 Geoethics.pdf.

Panizza, M. (1989). Beni geologici e cultura del paesaggio, In: Atti Convegno Internazionale Accademia Nazionale dei Lincei (June 26-28, 1989), Roma, 85-86.

Panizza, M., and S. Piacente (1991). Relationship between cultural resources and the natural environment, In: Proceedings of the European Symposium. Science, Technology and European Cultural Heritage (Bologna, June 13-16, 1989), Oxford, Butterworth-Heinemann, 787-793.

Panizza, M., and S. Piacente (2003). Geomorfologia culturale, Bologna, Pitagora Editrice.

Peppoloni, S. (2007). The problem of the scientific knowledge and the authoritativeness of the Earth sciences, In: Geoitalia 2007, Sesto Forum Italiano di Scienze della Terra (Rimini, September 12-14, 2007), Epitome; doi: 10.1474/Epitome.02.1318.Geoitalia2007.

Peppoloni, S. (2008). Riflessioni filosofiche sull'identità e l'autorevolezza delle Scienze della Terra, Geoitalia (Federazione Italiana di Scienze della Terra), 22, 3-6.

Peppoloni, S. (2009). Reflection cues on the cultural and social responsibility of the geologist in the third millennium, In: IX International Conference "New Ideas in Earth Sciences", 3rd vol., Russian State Geological Prospecting University, Moscow.

Peppoloni, S. (2011). Che cosa significa "Geoetica”? Dentro le parole, il senso dell'attività del geologo, Geoitalia (Federazione Italiana di Scienze della Terra), 34, 12-13.

Peppoloni, S. (2012a). Social aspects of the Earth sciences. Interview with Prof. Franco Ferrarotti, Annals of Geophysics, 55 (3), 347-348; doi:10.4401/ag-5632.

Peppoloni, S. (2012b). Ethical and cultural value of the 
Earth sciences. Interview with Prof. Giulio Giorello, Annals of Geophysics, 55 (3), 343-346; doi: 10.4401/ag5755.

Piacente, S. (1999). Sensibilità geologica e consenso sociale, Mem. Descr. Carta Geol. d'It., 54, 451-454.

Piacente, S., and G. Poli, eds. (2003). La memoria della Terra, la terra della Memoria, Bologna, L'inchiostroblu Editore.

Varet, J. (2007), Global approach to geoethics: a first attempt, In: Mining Pribram Symposium, International session on Geoethics (Pribram, Czech Republic), Abstract.

Contacts: Silvia Peppoloni, Giuseppe Di Capua, Istituto Nazionale di Geofisica e Vulcanologia, Rome, Italy; email: silvia.peppoloni@ingv.it, giuseppe.dicapua@ingv.it.

(C) 2012 by the Istituto Nazionale di Geofisica e Vulcanologia. All rights reserved. 